\title{
Development and Optimization of Process Parameters of Microwaved Cured Polymer Based Natural Fibre (Coir) Reinforced Composite
}

\author{
Shubham Singh ${ }^{1}$, Jitendra Sharma ${ }^{1}$, Ujjwaldeep ${ }^{1}$, Krishna Gupta ${ }^{1}$, Manabendra Saha ${ }^{2}$ \\ ${ }^{1}$ Student, 2 Sr. Assistant Professor \\ 1,2Deparmentt of Mechanical Engineering, ABES Engineering College, Ghaziabad, Uttar Pradesh, India
}

\begin{abstract}
How to cite this paper: Shubham Singh | Jitendra Sharma | Ujjwaldeep | Krishna Gupta|Manabendra Saha "Development and Optimization of Process Parameters of Microwaved Cured Polymer Based Natural Fibre (Coir) Reinforced Composite" Published in International Journal of Trend in Scientific Research and Development (ijtsrd), ISSN: 24566470, Volume-3 | Issue-4, June 2019, pp.93-97, URL: https://www.ijtsrd. com/papers/ijtsrd2 3595.pdf

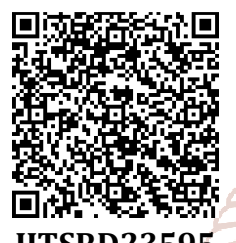

IITSRD23595
\end{abstract}

Copyright (C) 2019 by author(s) and International Journal of Trend in Scientific Research and Development Journal. This is an Open Access article distributed under the terms of the Creative Commons

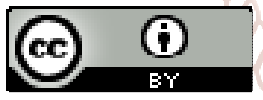
Attribution License (CC BY 4.0) (http://creativecommons.org/licenses/ by $/ 4.0$ )

Their advantages include having low density and cost, high specific strength, and being sustainable and environmentally friendly. The resulting products from those composites can be both reused and incinerated and do not have to be land filled as glass Fibre compounds, which can help in developing cars according to the EU end-of-life directive.. Lots of work has been carried out in the production of natural fibre reinforced polymer composites, using natural fibres like coir, hemp, cotton, sisal, kenaf, bagasse, areca, abaca, bamboo etc. and their properties have been studied. Here is an attempt made on the literature survey of areca fibre reinforced polymer composites where different properties ofarecafibres, its maturity level, surface treatment effect on properties of fibres.

\subsection{Natural Fibres}

Some of the natural and synthetic fibres that can be used for making composites are discussed below.

\section{ABSTRAC'}

a days the processing of natural Fibre reinforced polymer composite their low cost and light wpight that type of load capacity areas. Processing of NFRPC depends on a large no factors. Due to practical constraint 3 domen parameters were considered during experimental vestigation. The value of the parameter were selected on the basis of material mere determined for improvement ultimate tensile strength. The micte by using optimized parameters prepared and table was shown Curing Time is one of the main crucial parameter which affects the composite processing.

\section{KEYWORDS: Scientific research, challenges, literature review}

\section{INTRODUCTION}

Natural Fibres, any hair like raw material directly obtainable from a vegetable, an asive, low cost, and bio-degradability. Due to these characteristics, hecome attractive to researchers and scientists as an the synthetic and fibre glass as reinforcement composite gained the attention of the young scientists. NFCs have good potential for both interior and exterior automotive applications.

\subsubsection{Jute}

Jute is one of the most important natural Fibres now a days, and second only to cotton in the amount produced and variety of uses. Jute Fibres are extract from the plant which contained with Materials cellulose and lignin. The industrial term for jute Fibre is raw jute. The Fibres are off-white to brown, and 1-3 meters (3-10 feet) long. Jute is also called the golden Fibre for its color. The figure 1 shows the sample of jute Fibre used.

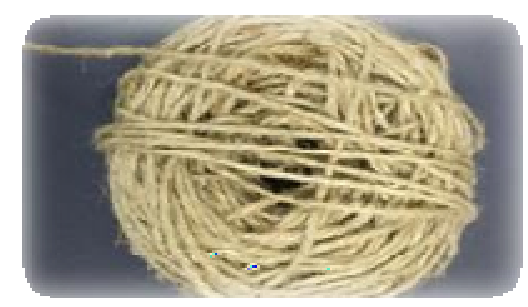

Figure 1 Jute Fibre 


\subsubsection{Coir}

Coir or coconut fibre, is a natural fibre extracted from the husk of coconut and used in products such as floor mats, doormats, brushes and mattresses. Coir is the fibrous material found between the hard, internal shell and the outer coat of a coconut. Other uses of brown coir (made from ripe coconut) are in upholstery padding, sacking and horticulture. White coir, harvested from unripe coconuts, is used for making finer brushes, string, rope and fishing nets. It has the advantage of not sinking, so can be used in long lengths on deep water without the added weight dragging down boats and buoys. The figure 2 shows the coir Fibre used.

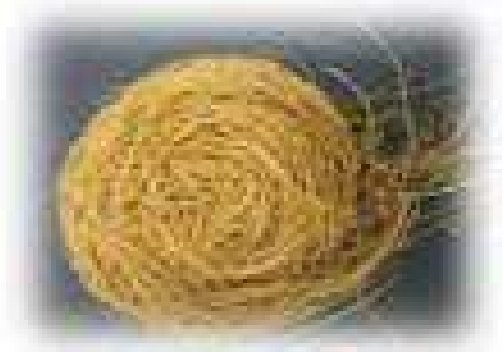

Figure 2 Coir Fibre

\subsection{Synthetic Fibres}

There are so many types of synthetic fibre are available in the market.

\subsubsection{Glass Fibre}

Glass fibre shown in Figure 4 is made of numerous extremely fine fibres of glass, commonly used as an insulating material. It is also used as a reinforcing agent for polymer products to produce strong and light sheets of Fibre-reinforced Polymer (FRP) popularly known as fibre glass. Glass fibres are not strong and rigid as carbon fibre, but are much cheaper and significantly less brittle. Figure 3 shows the a sample of glass fibre.

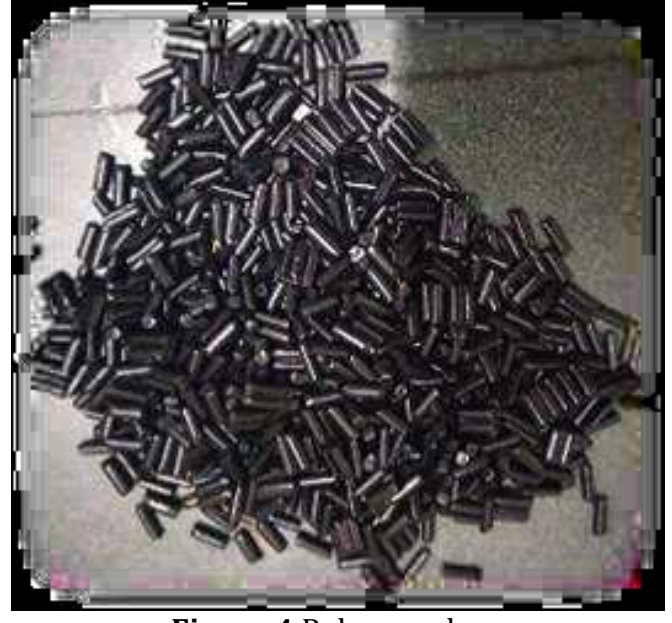

Figure 4 Polypropylene

\subsection{Materials}

In the present work, homopolymerized granules of polypropylene were supplied by Seth Plastic Industries, Delhi, India and coir fibre were supplied from India mart website.

In this research article i.e. Coir Fibre was used as a raw material. The Fibre was chopped at different size like $20 \mathrm{~mm}$, $30 \mathrm{~mm}$ and $40 \mathrm{~mm}$. Table 1 shows the physical properties of coir fibre.

Table 1: Physical Properties of Coir Fibre

\begin{tabular}{|c|c|c|}
\hline SI. No & Physical Property & Value \\
\hline 1 & Density (g/cm3) & 1.23 \\
\hline ntil 2 C & Tensile Strength $(\mathrm{kN} / \mathrm{mm} 2)$ & $210-220$ \\
\hline 3 & Stiffness (kN/mm) & $12-32$ \\
\hline 4 & Elongation at break (\%) & $10-20$ \\
\hline 5 & Moist Absorption (\%) & 5 \\
\hline 6 & Price of raw Fibre(Rs./kg) & $30-50$ \\
\hline
\end{tabular}

\subsection{Chemical Treatment}

Chopped coir fibre (20 $\mathrm{mm}$ to $40 \mathrm{~mm}$ ) were washed by distilled water at $85^{\circ} \mathrm{C}$ for 80 minutes and then dried it .For alkali treatment $10 \mathrm{wt} . \%$ solution of $\mathrm{NaOH}$ was prepared and washed fibres were soaked into solution for 4 hours at room temperature. After this, fibres were washed with distilled water and dried into hot air oven at $80^{\circ} \mathrm{C}$ for 2 hours.

Figure 3 Glass Fibre

\subsection{Matrices}

Polypropylene (PP), widely used, is a thermoplastic polymer seen in packaging and labelling, textiles, stationery, plastic, etc

\subsubsection{Polypropylene}

Polypropylene (PP), is a thermoplastic polymer used in a wide variety of applications. It is produced through chaingrowth polymerization from the monomer propylene. Polypropylene belongs to the group of polyolefin and is particularly crystalline. Its properties are similar to polyethylene, but it is slightly harder and more heat resistant. It is a white, mechanically rugged material and has a high chemical resistance.

Polypropylene is the second-most widely produced commodity plastic (after polyethylene) and it is often used in packaging and labelling. In 2014, the global market for polypropylene was about 65 million tones. The figure 4 shows the polypropylene polymer used.

\subsection{Manufacturing of composite}

The following steps were followed for making natural fibre reinforces composite.

Step 1. Domestic microwave was used as the primary source for making composite. Polymer composites come in the category of mixed microwave absorbing materials as absorption of microwave energy is dependent on the dielectric properties of the matrix as well as reinforcements.

Step 2. The treated fibre were chopped into 3 categories like $25 \mathrm{~mm}, 20 \mathrm{~mm}$, and $15 \mathrm{~mm}$.

Step 3. Bone china was taken as mold material for getting desired shape and size.

Step 4. The another properties like power and time was taken the process parameter.

Step 5. Power range $720 \mathrm{~W}, 640 \mathrm{~W}$ and $560 \mathrm{~W}$ and Time slot $16 \mathrm{~min}, 18 \mathrm{~min}, 20 \mathrm{~min}$.

Step 6. After completed the production process composite was taken and was being ready for mechanical testing. 
Taguchi design of the experiment is a simple optimization technique which is used for reducing the no of conducting experiemnts.In this experiment procedure, the three factors were selected with their level which is shown in the table no 2. Depending on different process parameters, the composite was prepared. Nine specimen with unique dimension was ready for tensile test.Tensile test specimens are fabricated as per ASTM standard and a test specimen is shown in fig 2 .

Table 2: Level and parameters of Experiments

\begin{tabular}{|c|c|c|c|c|}
\hline Symbol & Parameter & Level 1 & Level 2 & Level 3 \\
\hline A & $\begin{array}{c}\text { Power } \\
\text { (Watt) }\end{array}$ & 720 & 640 & 560 \\
\hline B & $\begin{array}{c}\text { Operational } \\
\text { time (min) }\end{array}$ & 16 & 18 & 20 \\
\hline C & $\begin{array}{c}\text { Fibre size } \\
\text { (mm) }\end{array}$ & 25 & 20 & 15 \\
\hline
\end{tabular}

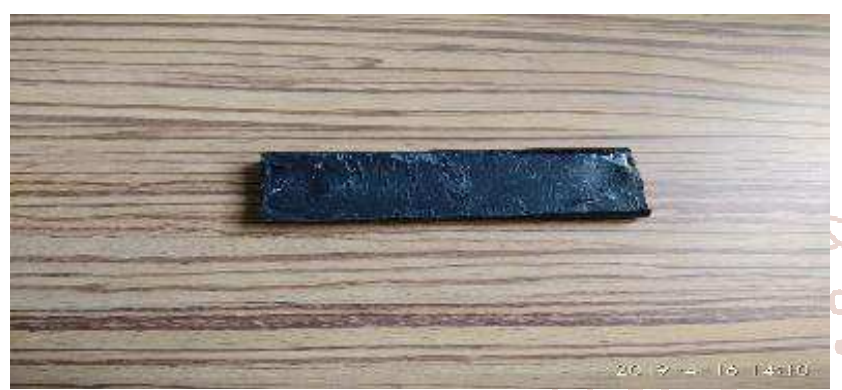

Figure: 5 Sample of NFRPC

In the present experimental work, an L9 Orthogonal Array with 3 rows and 3 column was used. This array can handle three level process parameters. Nine experiments were conducted to study the process parameters using the $\mathrm{L} 9$ OA.OA and the corresponding values of process parameters are listed in Table 3.

Table 3: Values of parameters, UTS and S/N ratio

\begin{tabular}{|c|c|c|c|c|c|}
\hline $\begin{array}{c}\text { S } \\
\text { No }\end{array}$ & $\begin{array}{c}\text { Power } \\
\text { A }\end{array}$ & $\begin{array}{c}\text { Opr. } \\
\text { Time } \\
\text { B }\end{array}$ & $\begin{array}{c}\text { Fibre } \\
\text { size } \\
\text { C }\end{array}$ & $\begin{array}{c}\text { Result } \\
\text { in } \\
\text { UTS }\end{array}$ & $\begin{array}{c}\text { S/N } \\
\text { RATI0 }\end{array}$ \\
\hline 1 & 720 & 16 & 25 & 28.2 & 29.01 \\
\hline 2 & 720 & 18 & 20 & 29.1 & 29.27 \\
\hline 3 & 720 & 20 & 15 & 30.3 & 29.63 \\
\hline 4 & 640 & 16 & 20 & 30.4 & 29.66 \\
\hline 5 & 640 & 18 & 15 & 30 & 29.54 \\
\hline 6 & 640 & 20 & 25 & 28.9 & 29.22 \\
\hline 7 & 560 & 16 & 15 & 28.1 & 29.97 \\
\hline 8 & 560 & 18 & 25 & 28.4 & 29.07 \\
\hline 9 & 560 & 20 & 20 & 29.4 & 29.37 \\
\hline
\end{tabular}

From S/N ratio, Noise factors are those uncontrollable factors which affect the process result (Output), whereas final response is known as the signal. The variation of the index is known as $\mathrm{S} / \mathrm{N}$ ratio. Variations are usually three types i, e "lower is better", "higher is better" and "Normal is better". In the Present study depending upon the criteria Ultimate tensile strength (UTS), Ultimate tensile strength (UTS) consider as "higher is better". In order to evaluate the influence of each selected factor on the response, $\mathrm{S} / \mathrm{N}$ ratios for each control factor was calculated.

$$
\begin{gathered}
\frac{S}{N}=-10 \log _{10}\left(\sum_{i=0}^{n} \frac{1}{y_{i}^{2}}\right), \text { Higher is better } \ldots \ldots 1 \\
\text { Table: } 4 \text { Response Value }
\end{gathered}
$$

\begin{tabular}{|c|c|c|c|}
\hline Level & Power A & Opr.Time B & Fibre size C \\
\hline 1 & 29.14 & 29.21 & 29.38 \\
\hline 2 & 29.47 & 29.30 & 29.43 \\
\hline 3 & 29.30 & 29.40 & 29.10 \\
\hline Delta & 0.34 & 0.19 & 0.34 \\
\hline Rank & 2 & 3 & 1 \\
\hline
\end{tabular}

\subsection{Tensile strength}

Ultimate tensile strength (UTS) was calculated experimentally, Taguchi technique was applied for analysis with support of ANOVA and mode of fracture was studied. On the basis of data analyzed, plots for $\mathrm{S} / \mathrm{N}$ ratio are shown in fig 4.it is much cleared that third level of Power ( $640 \mathrm{w}$ ), the second level of Operational Time (20 min) and third level of Fibre Size $(20 \mathrm{~mm})$ gives higher tensile strength.

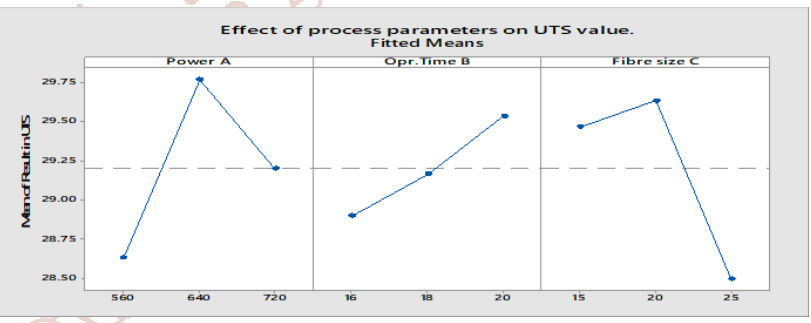

Figure 6 Effect of Process Parameters on UTS Value

\subsection{ANOVA}

Analysis of variance (ANOVA) was used to investigate the effects of various design parameters on microwave curing characteristics. The analysis was carried out at $95 \%$ confidence level.ANOVA result for Ultimate tensile strength (UTS) is given in table 5, shows that Fibre Size has the most significant effect with $35.78 \%$, while Power and Operational Time having least effect.

Table 5: ANOVA Table

\begin{tabular}{|c|c|c|c|c|c|c|}
\hline Source & DOF & SS & MS & F- Ratio & P- Value & \% of contribution \\
\hline Power & 2 & 1.9267 & 0.9633 & 1.28 & 0.438 & 30.68 \\
\hline Opr. Time & 2 & 0.6067 & 0.3033 & 0.40 & 0.712 & 9.66 \\
\hline Fibre size & 2 & 2.2467 & 1.1233 & 1.50 & 0.400 & 35.78 \\
\hline Error & 2 & 1.5000 & 0.7500 & & & 23.88 \\
\hline Total & 8 & 6.2800 & & & & \\
\hline
\end{tabular}




\subsection{Conclusions}

In this study to investigate the effect of Microwave processes on different process parameters was observed. Power, Fibre size, Operational Time were the variable parameters.

Following conclusion was drawn from the experiments and analysis of results.

1. In this experimental work, the selection of the process parameters for microwave curing with better quality has been presented.

2. Surface level is better by this process.

3. It is also observed from experimental work that mechanical properties depend on the fibre strength.

4. Taguchi technique is method power pull tool to discover the effect of microwave process parameters on mechanical quality.

5. ANOVA (Analysis of variance) depicts that operational time having a significant parameter that affects the UTS followed by power and fibre size.

6. Ductile fracture mode observed with fine dimples for tensile test samples.

\section{References}

[1] F. Ahmad, P.K. Bajpai, Evaluation of stiffness in a cellulose Fibre reinforced epoxylaminates for structural applications: Experimental and finite element analysis, Def. Technol. 14 (2018) 278-286.

[2] K.P. Ashik, R.S. Sharma, A Review on Mechanical Properties of Natural Fibre Reinforced Hybrid Polymer Composites, (2015) 420-426.

[3] P.K. Bajpai, I. Singh, J. Madaan, Joining of natural Fibre reinforced composites using microwave energy: Experimental and finite element study, Mater. Des. 35 (2012) 596-602.

[4] M.P. Ho, H. Wang, J.H. Lee, C.K. Ho, K.T. Lau, J. Leng, D. Hui, Critical factors on manufacturing processes of natural fibre composites, Compos. Part B Eng. 43 (2012) 3549-3562.

[5] M.M. Kabir, H. Wang, K.T. Lau, F. Cardona, Tensile properties of chemically treated hemp fibres as reinforcement for composites, Compos. Part B Eng. 53 (2013) 362-368.

[6] S.S. Kamath, D. Sampathkumar, B. Bennehalli, A review on natural areca fibre reinforced polymer composite materials, Cienc. e Tecnol. Dos Mater. 29 (2017) 106128.

[7] N.K. Kim, R.J.T. Lin, D. Bhattacharyya, Composites : Part B Extruded short wool fibre composites : Mechanical and fire retardant properties, Compos. PART B. 67 (2014) 472-480.

[8] N.R. Kumar, C.H. Ranga, P. Srikant, B.R. Rao, Mechanical properties of corn Fibre reinforced polypropylene composites using Taguchi method, Mater. Today Proc. 2 (2015) 3084-3092.

[9] Y. Li, L. Cheng, J. Zhou, Curing multidirectional carbon Fibre reinforced polymer composites with indirect microwave heating, Int. J. Adv. Manuf. Technol. 97 (2018) 1137-1147.

[10] Z. Li, A. Haigh, C. Soutis, A. Gibson, X-band microwave characterisation and analysis of carbon fibrereinforced polymer composites, Compos. Struct. 208
(2019) 224-232.

[11] Y.R. Loh, D. Sujan, M.E. Rahman, C.A. Das, Resources , Conservation and Recycling Sugarcane bagasse - The future composite material: A literature review, "Resources, Conserv. Recycl. 75 (2013) 14-22.

[12] A.A. Mohammed, D. Bachtiar, M.R.M. Rejab, J.P. Siregar, Effect of microwave treatment on tensile properties of sugar palm fi bre reinforced thermoplastic polyurethane composites, Def. Technol. (2018) 8-11.

[13] L. Mohammed, M.N.M. Ansari, G. Pua, M. Jawaid, M.S. Islam, A Review on Natural Fibre Reinforced Polymer Composite and Its Applications, Int. J. Polym. Sci. 2015 (2015).

[14] S.V. Mohan, M.V. Reddy, Bioresource Technology Optimization of critical factors to enhance polyhydroxyalkanoates ( PHA ) synthesis by mixed culture using Taguchi design of experimental methodology, Bioresour. Technol. 128 (2013) 409-416.

[15] G.B. Narasimha, M.V. Krishna, R. Sindhu, Prediction of Wear Behaviour of Almg1sicu Hybrid MMC Using Taguchi with Grey Rational Analysis, Procedia Eng. 97 (2014) 555-562.

[16] G. Petrone, S. Rao, S. De Rosa, B.R. Mace, F. Franco, D. Bhattacharyya, Behaviour of fibre-reinforced honeycomb core under low velocity impact loading, Compos. Struct. 100 (2013) 356-362.

[17] K.L. Pickering, M.G.A. Efendy, T.M. Le, A review of recent developments in natural fibre composites and their mechanical performance, Compos. Part A Appl. Sci. Manuf. 83 (2016) 98-112.

[18] R. Potluri, V. Diwakar, K. Venkatesh, B. Srinivasa Reddy, Analytical Model Application for Prediction of Mechanical Properties of Natural Fibre Reinforced Composites, in: Mater. Today Proc., Elsevier Ltd, 2018: pp. 5809-5818.

[19] V. Prasad, A. Joy, G. Venkatachalam, S. Narayanan, S. Rajakumar, Finite Element analysis of jute and banana fibre reinforced hybrid polymer matrix composite and optimization of design parameters using ANOVA technique, Procedia Eng. 97 (2014) 1116-1125.

[20] M. Ramesh, Flax (Linum usitatissimum L.) fibre reinforced polymer composite materials: A review on preparation, properties and prospects, Prog. Mater. Sci. 102 (2019) 109-166.

[21] M. Sadia, L. Jee, S. Hossain, L. Siong, The influence of addition of treated kenaf fibre in the production and properties of fibre reinforced foamed composite, Constr. Build. Mater. 178 (2018) 518-528.

[22] A. Sailesh, R. Arunkumar, S. Saravanan, ScienceDirect Mechanical Properties and Wear Properties of Kenaf Aloe Vera - Jute Fibre Reinforced Natural Fibre Composites, Mater. Today Proc. 5 (2018) 7184-7190.

[23] Z. Salleh, M.N. Berhan, K. Mei, Y.M. Taib, A. Kalam, N.R.N. Roselina, Open Hole Tensile Properties of Kenaf Composite and Kenaf / Fibreglass Hybrid Composite Laminates, Procedia Eng. 68 (2013) 399- 404.

[24] M.R. Sanjay, P. Madhu, M. Jawaid, P. Senthamaraikannan, S. Senthil, S. Pradeep, Characterization and properties of natural Fibre 
polymer composites: A comprehensive review, Elsevier B.V., 2018.

[25] K. Senthilkumar, N. Saba, N. Rajini, M. Chandrasekar, M. Jawaid, S. Siengchin, O.Y. Alotman, Mechanical properties evaluation of sisal fibre reinforced polymer composites : A review, Constr. Build. Mater.174 (2018) 713-729.

[26] M.K. Singh, S. Zafar, Development and mechanical characterization of microwave-cured thermoplastic based natural fibre reinforced composites, (2018) 116.

[27] M.K. Singh, S. Zafar, Influence of microwave power on mechanical properties of microwave-cured polyethylene / coir composites, J. Nat. Fibres. 00 (2018) $1-16$.

[28] M. Sood, G. Dwivedi, Effect of Fibre treatment on flexural properties of natural Fibre reinforced composites: A review, Egypt. J. Pet. 27 (2018) 775-783.

[29] R. Sreenivasulu, Optimization of Surface Roughness and Delamination Damage of GFRP Composite Material in
End Milling using Taguchi Design Method and Artificial Neural Network, Procedia Eng. 64 (2013) 785-794.

[30] J. Summerscales, N. Dissanayake, A. Virk, W. Hall, A review of bast fibres and their composites. Part 2 Composites, Compos. Part A Appl. Sci. Manuf. 41 (2010) 1336-1344.

[31] G. TITTO JOHN, M. K.T., Microwave and Conventional Curing of Polymer Matrix Composites Reinforced With Natural Fibres of Kerala, I-Manager's

[32] J. Mater. Sci. 5 (2018) 24. T.N. Valarmathi, K. Palanikumar, B. Latha, Measurement and analysis of thrust force in drilling of particle board ( PB ) composite panels, Measurement. 46 (2013) 12201230.

[33] D. Verma, P.C. Gope, A. Shandilya, A. Gupta, M.K. Maheshwari, Coir fibre reinforcement and application in polymer composites: A review, J. Mater. Environ. Sci. 4 (2013) 263-276.

[34] Alkalichemical Treatment on the Surface of, 4 (2015) 172-178.

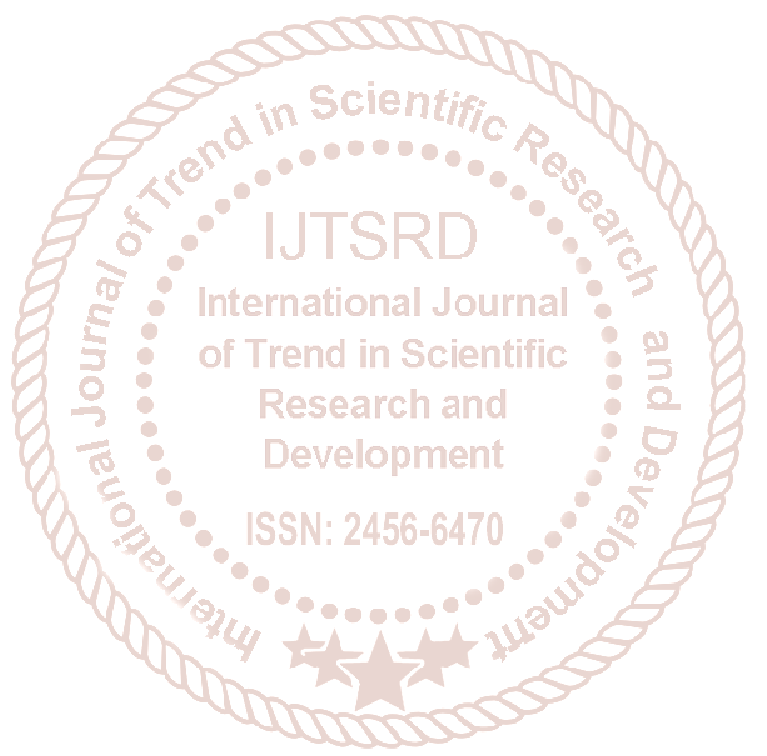

